Academic Platform Journal of Engineering and Science

journal homepage: http://apjes.com/

\title{
Yapım Firmalarının Kurumsal Risk Yönetimi Olgunluğunda Risk Yöneticisinin Rolü
}

\author{
*1 Tuğçe Ercan, ${ }^{2}$ Kübra Arı \\ ${ }^{1}$ YTÜ Mimarlık Fakültesi, tugcesim@yahoo.com \\ ${ }^{2}$ YTÜ Mimarlık Fakültesi, kubra.ari2@gmail.com
}

\section{$\ddot{O} z$}

Risk yönetim sürecini bütüncül bir yaklaşımla ele alan kurumsal risk yönetimi (KRY), verimli iş süreçlerinin yürütülmesine olanak sağlamaktadır. Sürekli olarak gelişen yapım sektöründe, karmaşık hale gelen projeler için süre, maliyet ve kalite faktörlerinde başarıya ulaşmak sistemli ve bütünsel yönetim yaklaşımlarını gerekli kılmaktadır. Yapım projelerinin yönetim sürecinde, olası riskleri bütünsel bir bakış açısıyla yönetebilmek, yapım projelerinin başarı ve verimliliği açısından kritik önem taşımaktadır. Ancak yapım sektöründe faaliyet gösteren firmalarda, proje düzeyinde risk yönetiminden kurumsal risk yönetimine geçiş adımları atılmaya yeni yeni başlanmıştır ve henüz yeterli olgunluk seviyesine ulaşılamamıştır.

Bu bağlamda bu çalışmanın temel amacı, risk yöneticisinin varlığının ve KRY yapılaşmasının yapım firmalarının kurumsal risk yönetimi olgunluk düzeyine olan etkisini ortaya koymaktır. Bu amaçla, yapılan kapsamlı literatür taraması sonucunda elde edilen altı temel faktör (yönetim kurulu ve üst düzey yönetimin kararlılığı, kurumsal risk yönetimine sahip olma, risk tanımlama, analiz ve tepkisi, kurumsal risk yönetiminin iş süreçlerine entegre edilmesi, hedeflerin belirlenmesi ve yeterli kaynaklar) baz alınarak bir anket alan çalışması düzenlenmiştir. Veriler, betimsel istatistikler ve ANOVA analizi yöntemleriyle irdelenmiştir. Yürütülen çalışma sonucunda risk yöneticisi varlığının yapım firmalarında kurumsal risk yönetimi olgunluk düzeyine olan etkisi ve temel faktörlerin KRY olgunluğuna olan etki ve önem dereceleri belirlenmiş ve karşılaştırmıştır. Bu çalışma, yapım firmalarında KRY olgunluk düzeylerine ilişkin kavramsal çerçeveyi irdeleyerek, yapılacak gelecek çalışmalara 1şık tutmuştur.

Anahtar Kelimeler: yapım yönetimi, kurumsal risk yönetimi, kurumsal risk yönetimi olgunluğu, risk yöneticisi.

\section{The Role of the Risk Manager in Enterprise Risk Management Maturity Level of Construction Companies}

\author{
*1 Tuğçe Ercan, ${ }^{2}$ Kübra Arı \\ ${ }^{1}$ YTÜ Mimarlık Fakültesi, tugcesim@yahoo.com \\ ${ }^{2}$ YTÜ Mimarlık Fakültesi, kubra.ari2@gmail.com
}

\begin{abstract}
Addressing the risk management process with a holistic approach, enterprise risk management (ERM) enables efficient business processes to be carried out. Achieving success in time, cost and quality factors for complex projects in the constantly evolving construction industry requires systematic and holistic management approaches. In the management process of the construction projects, managing the possible risks from a holistic perspective is critical to the success and efficiency of the construction projects. However, in the companies operating in the construction sector, the transition steps from project-level risk management to corporate risk management have just begun and the level of maturity has not yet been reached.
\end{abstract}

In this context, the main purpose of this study is to reveal the effect of the existence of the risk manager and corporate risk managament structuring on the corporate risk management maturity level of the construction companies. For this purpose, six main factors (stability of the board and senior management, having corporate risk management, risk identification, analysis and response, integrating corporate risk management into business processes, setting targets, and sufficient resources) are obtained as a result of a comprehensive literature review and a survey field study was organized. The data were analyzed with descriptive

${ }^{* 1}$ Sorumlu yazar adres, mail ve telefon bilgileri (sadece ilk sayfada olacaktır) / Corresponding author address, mail and telephone (only on the first page) 
statistics and ANOVA analysis methods. As a result of the study carried out, the effect of the presence of the risk manager on the maturity level of corporate risk management in the construction companies and the impact and importance levels of the basic factors on the maturity of ERM were determined and compared. This study shed light on future studies to be done by examining the conceptual framework regarding ERM maturity levels in production companies.

Keywords: construction management, enterprise risk management (ERM), enterprise risk management maturity, risk manager.

\section{GÍRIŞ}

Kurumsal risk yönetimi (KRY) ile ilgili 1995 yılından bu yana yapılan tanımlamalarda KRY'nin risk analiz süreçlerindeki etkisine, stratejik amaç ve hedeflere ulaşmadaki rolüne, maliyet planlamaları ile firma ve paydaş değerleri üzerindeki etkisine ve bütüncül bir yaklaşım oluşuna vurgu yapılmıştır. Tüm tanımlar arasından COSO (Committee of Sponsoring Organizations) modelinin tanımı en kapsamlı KRY tanımı olarak nitelendirilebilir, bu tanıma göre KRY:

'bir kuruluşun üst yöneticilerinden ve çalışanlarından etkilenen, kurumsal bir stratejiyle uygulanan, kuruluşu etkileyebilecek potansiyel olayları tanımlama için tasarlanan, risk alabilme sinırları ölçüsünde riskleri yöneten ve kuruluşun hedeflerine ulaşma başarısını gözeterek makul güvence sağlayan süreçtir.' [1].

Son zamanlarda terkedilen bir yaklaşım olan geleneksel risk yönetimi, firmayı risklerin ters etkilerinden korumay1 amaçlamaktadır. Buna karşın KRY ise, firmanın genel stratejisinin bir parçası olur, firmanın riske dayalı karar mekanizmalarını özümsemesini sağlar ve piyasa değerini artırarak risk yönetim sürecini gerçekleştirir. Ayrıca, risklerin kategorize edilerek ele alındığı geleneksel risk yönetiminin aksine KRY, çeşitlilik içeren riskleri entegre ederek bütüncül bir şekilde ele alır ve süreçlere entegre eder. COSO (2004) tarafından oluşturulan KRY çerçevesinde KRY temel unsurları olan iç çevre, hedeflerin belirlenmesi, olay tanımlaması, risk değerlendirmesi, risk tepkisi, kontrol faaliyetleri, bilgi ile iletişim ve gözlemleme unsurları KRY sürecini özetleyen basamaklardır [1].

KRY sürecinde, KRY'nin sunduğu bütüncül yaklaşımla, riskler tanımlanır, risk toleransı göz önüne alınarak uygun tepkiler üzerine yoğunlaşılır, karar verme mekanizmaları iyileşir ve firma içindeki tüm birimlerde genel bir risk yönetimi farkındalığı oluşturulur [2]. Bir diğer yandan, KRY uygulamalarının proje süreçlerine ve firma faaliyetlerine etkilerinin de belirli aralıklarla ölçülmesi ve kontrol edilmesi gerekmektedir.

Zaman, maliyet ve kalite yönetim süreçlerini içeren karmaşık bir planlama ağına sahip yapım projelerinin döngüsü içinde yapım firmalarının risklerle karşılaşması kaçınılmazdır. Bu planlamaların istenilen düzeyde ilerlemesi için yapılan risk yönetim faaliyetleri çoğu firma tarafindan proje düzeyinde ele alınmaktadır [3]. Ancak proje düzeyinde kalan geleneksel risk yönetim süreçleri değişen piyasa koşullarında önemli noktaların gözden kaçırılmasına [4], zaman, maliyet ve kalite kayıplarına sebep olarak proje süreçlerine zarar vermektedir. Bu yüzden yapım firmalarında risk yönetim süreçlerinin sadece proje düzeyinde değil, kurumsal anlamda örgütün her alanına yayılan, daha bütüncül yaklaşım olan KRY ile yönetilmesi sürdürülebilir firma performansı için bir gerekliliktir [5].

Farklı risk gruplarıyla yüzleşmenin olası olduğu yapım sektöründe KRY konusunda yapılan çalışmaların sayısının sınırlı olması ve yapım sektöründeki firmalarının KRY olgunluk düzeylerinin incelenmesinin ve bu konudaki eksikliklerinin saptanması noktasında bir farkındalık oluşturması bu çalışmanın temel amacıdır.

$\mathrm{Bu}$ çalışmanın temel hipotezi ise, etkili KRY süreçleri için gerekli bir etmen olan risk yöneticisin varlığının yapım firmalarının KRY olgunluk düzeyine de olumlu etki edeceğidir. Bu bağlamda bu çalışma 6 anahtar KRY faktörü ve anahtar faktörlerin 16 alt parametresi ele alınarak belirlenecek KRY olgunluk düzeyine risk yöneticisinin varlığının etkisini incelemek amacındadır. Bir diğer yandan, KRY yapılaşma düzeyleri, KRY olgunluğu ve risk yöneticisinin varlığıyla ilişkileri de incelenerek KRY olgunluğuna etkisinde öne çıkan faktörler ve parametreler araştırılacaktır.

\section{RISKK YÖNETIMINE YENI BİR PERSPEKTIIF: KURUMSAL RISK YÖNETIMİ(KRY)}

\subsection{Kurumsal Risk Yönetimi Yaklaşımı}

Literatürdeki birçok çalışma, kurumların stratejik hedeflerine ulaşması, risklerin analizi, ölçülmesi ve tepki verilmesi, tehditlerin değerlendirilmesi ve yeterli risk iştahı içinde olarak firsatlardan yararlanılması, şirket değerinin artması, maliyet/fayda analizlerinde KRY' nin rolüne vurgu yapmaktadır. Literatürdeki KRY tanımlarında ise bütüncül bir yaklaşım oluşuna sıklıkla değinilmiştir, bunun yanı sıra KRY'nin iş süreçlerine etki ediş şekilleri ve potansiyel faydalarına odaklanan çalışmalar da dikkat çekmektedir. Literatürdeki KRY tanımlamalarını dört temel başlık içinde ele almak uygun olacaktır.

\subsubsection{KRY'nin risk analiz süreçlerindeki etkisi üzerinden tanımlanması}

Holton (1996), KRY'yi risklerin analiz sürecini optimize etmekle ilgili bulurken [6], Deragon (2000) KRY'yi varyasyonları en aza indirgemek, doğuştan gelen riskleri azaltmak ve pozitif sinerjileri artırmak için sistematik ilişkileri yönetmeyi amaçlayan bir yaklaşım olarak tanımlamaktadır [7]. ISO 9001 standartlarında bir organizasyonu riskle ilgili yönlendirmek ve kontrol etmek 
için gerçekleştirilen koordineli faaliyetler olarak tanımlanan risk yönetimi, 'Risk and Insurance Management Society' ise örgüt hedeflerinin öncelikli olarak ele alınmasını vurgulayarak, risk tabanı çerçevesinde oluşturulan risk portföyünü hedeflere ulaşmada bir destek sistemi olarak yöneten stratejik bir iş disiplini olduğu belirtilmektedir.

\subsubsection{KRY'nin stratejik amaç ve hedeflere ulaşmadaki rolü üzerinden tanımlanması}

Banham (1999), KRY'nin hedefinin firma faaliyetlerinden kaynaklanan riskleri tanımlamak, analiz etmek, ölçmek ve karşılaştırmak olduğunu belirtirken [8], Miccolis (2000) KRY'yi stratejik hedeflere ulaşılmasını tehdit eden riskleri değerlendiren titiz bir yaklaşım olarak tanımlamaktadır [9]. IIA (2001) ise daha genel bir tanımlama yaparak, bir organizasyonun stratejik ve finansal hedeflerinin başarısını etkileyen girişimci ve yönetimsel yaklaşımın kurumsal risk yönetimi olduğunu savunmaktadır[10].

\subsubsection{KRY'nin maliyet planlamaları, firma ve paydaş değerleri üzerindeki etkisi üzerinden tanımlanması}

Firmaların finansal raporlarında KRY'nin firma ve paydaş değerleri üzerinde etkisi, literatürdeki KRY tanımlamalarında yer edinmiştir. KRY, stratejiyi, süreçleri, insanları, teknoloji ve bilgiyi bir araya getirerek bütüncül ve ileriye dönük bir yaklaşım çerçevesinde işletmenin değerini yükselten bir yaklaşımken, Tillinghast Perrin'e (2001) göre KRY, risklerin tehdit ve firsat olarak algilanarak değerlendirilip ticari amaçların gerçekleştirilmesine yön veren bir sistemdir [11]. D’archy ve Brogan (2001) ise ticari amaçları biraz daha özelleştirerek organizasyonların paydaşlarına değer katmak amacıyla riskleri tespit etme, kontrol etme, finanse etme ve gözlemleme sürecini KRY olarak tanımlamaktadır [12].

\subsubsection{KRY'nin bütüncül bir yaklaşım oluşu üzerinden} tanımlanması

Organizasyonların risklerinin yönetilmesinde rol alan KRY'nin bütüncül yaklaşımı, Dickinson [13], Harrington [14], Barton [15] ve Liebenberg ve Hoyt'un [16] KRY kavramlarında değinilen nokta olmuştur. Silo yaklaşımının tersine bütünleşmiş ve tanımlanmış, sürekli ve kapsamlı, sistematik ve entegre edilmiş, daha saldırgan ve stratejik KRY'yi tanımlamada kullanılan anahtar kelimeler olmuştur.

\subsection{Geleneksel Risk Yönetiminden Kurumsal Risk Yönetimine Geçiş}

21. yüzyıldan itibaren finansal kuruluş ve ortaklıklarda KRY anlayışına verilen destek ve KRY kullanıcıların sayısı artmıştır. Özellikle küresel kriz dönemlerinde risklerin düzgün tanımlanması, analizi ve yönetimine olanak sağlayan KRY anlayışı önem kazanmış, dünya çapında pek çok kuruluş başarısızlık ya da finansal zorluk dönemlerine girişi, düzenli bir risk yönetim sistemine sahip olmadıklarına bağlanmıştır [17].
Geleneksel risk yönetimi firmayı risklerin ters etkilerinden korumayı amaçlarken, KRY firmanın genel stratejisinin bir parçası olur ve firmaların riske dayalı karar mekanizmalarını özümseten bir yaklaşımla, firma hisselerinin de değer kazanarak risk yönetim sürecini gerçekleştirir.

Tablo 1 Geleneksel Risk Yönetimi ve Kurumsal Risk Yönetimi Özellikleri [31]

\begin{tabular}{|l|l|}
\hline GELENEKSEL RISK YÖNETIMI & KURUMSAL RISK YÖNETIMİ \\
\hline $\begin{array}{l}\text { Zayıf yapılaşma, merkezileşme } \\
\text { ve resmileșme }\end{array}$ & $\begin{array}{l}\text { Güçlü yapılaşma, merkezileşme } \\
\text { ve resmileșme }\end{array}$ \\
\hline $\begin{array}{l}\text { Ayrık risk kategorilerinin } \\
\text { oluşturulması }\end{array}$ & $\begin{array}{l}\text { Bütüncül risk kategorilerinin } \\
\text { oluşturulması }\end{array}$ \\
\hline $\begin{array}{l}\text { Risklerin tanımı, analizi ve } \\
\text { tepkisinin ayrı fonksiyon ve } \\
\text { departmanlara yönelik } \\
\text { gerçekleștirilmesi }\end{array}$ & $\begin{array}{l}\text { Risklerin tanımı, analizi ve } \\
\text { tepkisinin organizasyon } \\
\text { geneline yönelik } \\
\text { gerçekleștirilmesi }\end{array}$ \\
\hline $\begin{array}{l}\text { Silo-tabanlı perspektif } \\
\text { Bütüncül perspektif ve } \\
\text { entegrasyon }\end{array}$ \\
\hline $\begin{array}{l}\text { Kötü finans senaryolarına karşı } \\
\text { savunmacı/ korumacı tavırda } \\
\text { bulunma }\end{array}$ & $\begin{array}{l}\text { Riski minimize etmenin yanı } \\
\text { sıra potansiyel fırsatları } \\
\text { girişimci tavırda bulunma }\end{array}$ \\
\hline
\end{tabular}

Tablo 1'de geleneksel risk yönetimi ile kurumsal risk yönetimi anlayışlarının karşıllaştırılması yapılmıştır. Geleneksel risk yönetimi yapılaşma, merkezileşme ve resmileşme anlamında zayıf kalırken, KRY'de güçlü yapılaşma, merkezileşmiş ve resmileşmiş bir çerçeve vardır [31]. Silo tabanl1, departmanlara yönelik risklerin kategorize edilmesi, tanımı, analizi ve tepkisinin verildiği bir yaklaşım olan geleneksel risk yönetimin aksine, KRY organizasyon geneline yönelik bütünsel bir risk yönetim süreci önerir. Geleneksel risk yönetiminde risklerle karşılaşıldığında bürünülen savunmacı ve korumacı tavır, kötü finans senaryolarına ve sonuçlarına sebebiyet verirken, KRY süreçlerinde riskler minimize edilerek ve sadece tehdit olarak algılanmayı potansiyel firsatlar olarak değerlendirilerek yönetilir.

\subsection{Kurumsal Risk Yönetimi (KRY) İşleyişi}

KRY'nin firmalarda adaptasyonu ve işleyişi, yasalara uygunluk ve kurumsal yönetim gerekliliklerini şart koşmaktadır [18]. Amerika Birleşik Devletleri'nde bu gerekliliklerin kurallarını düzenleyen New York Stock Exchange ve Sarbanes- Oxley Act gibi kuruluşların yanında zorunlu olmayan raporları ve yönetim pratiklerini kıyaslama ve halkın baskısıyla oluşturuluş standartlar COSO KRY çerçevesinde bir araya getirilmiştir [19].

Şekil 1'de COSO'nun KRY çerçevesi yer almaktadır. COSO'nun KRY çerçevesi; risk unsurları, kurum içindeki birim bileşenleri ve kurumun stratejik amaç ve hedefleri olmak üzere üç boyuta sahiptir. Dahili çevre, hedeflerin belirlenmesi, risk değerlendirmesi, risk tepkisi, kontrol faaliyetleri, bilgi ve iletişim ve gözlemleme ise KRY'nin temel unsurları olarak yatay sütunda yer almaktadır. 


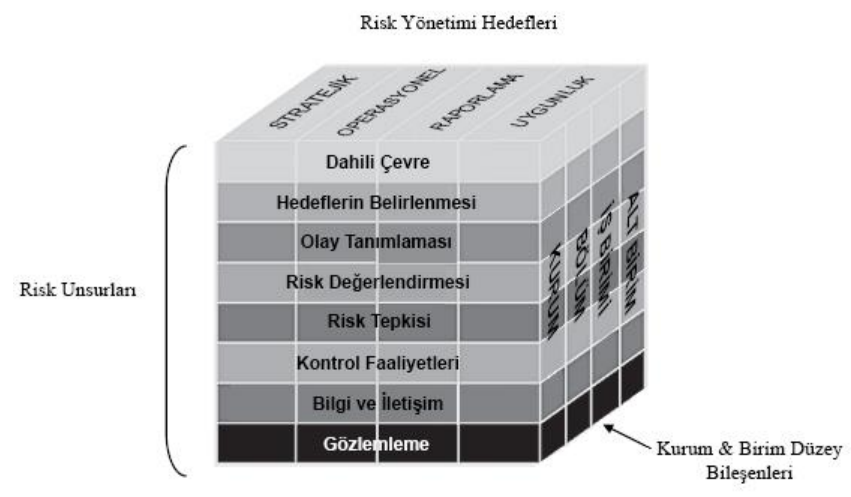

Şekil 1 COSO Kurumsal Risk Yönetimi (KRY) Çerçevesi

Kurum içindeki birim bileşenlerinin sayısı kurumların organizasyonel yapısına göre değişmekte olup, risk yönetimi hedefleri de kurumların stratejik amaç ve hedeflerine göre şekillenerek KRY çerçevesinde yerlerini almaktadır.

Yasa ve yönetmelikler, tüm bir endüstri için asgari standartları oluşturmak için tasarlanmış kült araçlardır, ancak her zaman en iyi uygulamaları temsil etmemektedir. Yasa ve yönetmeliklere uyum, herhangi bir risk yönetim programında önemli bir hedeftir, ancak bunun KRY başarısı için gerekli ancak yetersiz bir koşul olduğu göz önünde bulundurulmalıdir.

Gelişmiş KRY süreçleri platformunu oluşturan 4 gereksinim vardir [20].

Birincisi, stratejik hedeflerin ve organizasyonun gerektirdiği aktivitelerin gerçekleşmesine yönelik bir risk yönetim planı olmalıdir [20].

Íkincisi, risk yönetim süreçlerini destekleyen ve yön veren kaynakların tanımlanması ve gerekli kaynakların tedarik edilmesi, sorumlu ve otoritelerin görev tanımlarının yapılması, üst yönetimin kararlılığının ana hatlarını çizen bir planlama ve kaynak varlığı gereklidir.

Üçüncüsü, risk yönetim programlarının uygulamasını içeren süreçler belirtilmelidir.

Dördüncüsü ise, risk yönetim programlarının uygunluğunun ve verimliliğinin değerlendirilebilmesi için yönetimce ve periyodik olarak gözden geçirilmesi bir rutin haline getirilmelidir [20].

Kurumsal risk yönetiminin gerekliliklerinin sağlandığ durumlarda bile uygulamaya geçmek kolay değildir. Kurumsal risk yönetimi, uygulamalarında esnek örgütsel yap1 büyük önem taşımaktadır, KRY anlayışının firma tarafından benimsenmesi önemlidir. Üst düzey yöneticilerin risk yönetimi uygulamalarını desteklemesi, bir risk yönetimi planı geliştirmesi, yeterli risk yönetimi bilgi düzeyine sahip olması KRY anlayışının yerleşmesini kolaylaştırır [21].
Teknolojinin gelişmesi, fazla miktarda hesaplama gücü gerektiren kurumsal risk yönetimi için önemli bir dış anahtar etmen olmuştur. Gelişen teknoloji aracılığıyla, risklere, risklerin olasılıklarına, kesinlik derecelerine göre risklere, risklerin doğru ölçümüne ve risklerin birbirine bağlılık durumlarına ulaşılabilmektedir.

Başarılı kurumsal risk yönetimi programları, gelişmiş finansal stabilite, gelişmiş karar verme mekanizması, artan sorumluluk yönetimi, rekabet avantajı, kaynakların verimli kullanımı ve projelerin kontrolünde gelişmişlik sağlar [22].

\section{Yapım Sektöründe Kurumsal Risk Yönetimi (KRY): Literatür Taraması}

Yapım sektörü, içerdiği riskler bakımından, proje düzeyinde değil daha bütüncül bir risk yönetim yaklaşımına ihtiyaç duyar. Bu ihtiyaç doğrultusunda yapım firmaları, kurumsal risk yönetimi adaptasyon sürecinde olması gereken birincil sektördür.

Tablo 2 Yapım Sektöründe KRY Alanında Yapılan Çalışmalar

\begin{tabular}{|c|c|c|c|}
\hline YAZAR & TARİH & KONU & $\begin{array}{l}\text { YÖNTE } \\
\text { M }\end{array}$ \\
\hline $\begin{array}{l}\text { Zhao, Hwang ve } \\
\text { Low }\end{array}$ & 2013 & $\begin{array}{l}\text { KRY kritik başarı } \\
\text { faktörleri }\end{array}$ & Nicel \\
\hline $\begin{array}{l}\text { Zhao, Hwang ve } \\
\text { Low }\end{array}$ & 2013 & $\begin{array}{l}\text { Bulanık KRY Olgunluk } \\
\text { Modeli Geliştirme }\end{array}$ & Nicel \\
\hline $\begin{array}{l}\text { Zhao, Hwang ve } \\
\text { Low }\end{array}$ & 2014 & KRY Uygulamaları & Nicel \\
\hline Zhao & 2014 & $\begin{array}{l}\text { KRY Olgunluğunu } \\
\text { İnceleme }\end{array}$ & Nicel \\
\hline $\begin{array}{l}\text { Salawu ve } \\
\text { Fadhlin }\end{array}$ & 2015 & $\begin{array}{l}\text { Risk yönetimi } \\
\text { olgunluğunu } \\
\text { değerlendirme }\end{array}$ & Nicel \\
\hline Serpell vd. & 2015 & $\begin{array}{l}\text { Yapım firmalarında risk } \\
\text { yönetimi pratiklerini } \\
\text { inceleme }\end{array}$ & Nitel \\
\hline Zhao vd. & 2015 & $\begin{array}{l}\text { KRY Etmenleri ve } \\
\text { engelleri }\end{array}$ & Nicel \\
\hline $\begin{array}{l}\text { Zhao, } \\
\text { Hwang ve Low }\end{array}$ & 2016 & $\begin{array}{l}\text { KRY bilgi tabanlı karar } \\
\text { destek sistemi }\end{array}$ & Nitel \\
\hline $\begin{array}{l}\text { Renault, Agumba } \\
\text { ve Balogun }\end{array}$ & 2016 & KRY etmen ve zorlukları & Nitel \\
\hline $\begin{array}{l}\text { Zhao ve } \\
\text { Singhaputtangkul, }\end{array}$ & 2016 & $\begin{array}{l}\text { Firma Karakterinin KRY } \\
\text { Üzerindeki Etkisi }\end{array}$ & Nicel \\
\hline Caiado vd. & 2016 & $\begin{array}{l}\text { Risk Yönetimi } \\
\text { Olgunluğu Rehberi }\end{array}$ & Nitel \\
\hline $\begin{array}{l}\text { Mazlina } \quad \text { ve } \\
\text { Amirah }\end{array}$ & 2016 & KRY Uygulamaları & Nitel \\
\hline $\begin{array}{l}\text { Renault, Agumba } \\
\text { ve Ansary }\end{array}$ & 2016 & $\begin{array}{l}\text { KRY Süreçleri üzerine } \\
\text { Bir Değerlendirilme }\end{array}$ & Nitel \\
\hline $\begin{array}{l}\text { Wibowo ve } \\
\text { Taufik }\end{array}$ & 2017 & $\begin{array}{l}\text { Kamu İnşaat Projelerinin } \\
\text { Müşteri Organizasyonları } \\
\text { için Bir Öz } \\
\text { Değerlendirme Risk } \\
\text { Yönetimi Olgunluk } \\
\text { Modeli Geliştirilmesi }\end{array}$ & Nicel \\
\hline
\end{tabular}

Son zamanlarda kurumsal risk yönetimi anlayışının yayılmakta olduğu bir sektör olan yapım sektörü, bu alanda yapılan çalışmaların sayısının arttığı bir sektör olmuştur. Literatürde KRY'nin zorluk ve kolaylıklarının anlaşıımasını 
sağlayan, KRY başarı faktörlerini, uygulanma ve olgunluk düzeylerini ortaya koyan çalışmalar yapılmıştır (Tablo 2).

Yapım sektöründe KRY alanındaki çalışmalar, konu olarak KRY olgunluğu, KRY uygulamaları, KRY etmen ve zorlukları ve modeller geliştirerek gerçekleştirilmiştir.

Salawu ve Abdullah tarafindan 2015 yılında Nijerya'daki federal otoyol yapımı yüklenici firmalarının risk yönetim kabiliyetlerini ölçmeye yönelik yapılan araştırmada müteahhitlerin risk yönetim kabiliyet düzeyinin henüz olgunlaşmamış olduğu sonucuna varılmıştır.

Serpell vd. (2015) ise inşaat firmalarında risk yönetimi hakkında bilgi yetersizliği olduğunu öne sürmüşlerdir. Bilgi eksikliği konusunda bir farkındalık yaratmanın ve risk yönetimi konusundaki boşlukları tespit etmenin ve geliştirmenin ancak risk yönetimi konusundaki bilgi yönetimini her projede sistematik bir şekilde gerçekleştirerek mümkün olacağının vurgusu yapılmıştır [23].

Yapım firmalarında son yıllarda artan KRY konulu araştırmalar, KRY uygulamalarını inceleme, KRY olgunluğu analizi yapma, KRY olgunluk analizleri üzerinden öne çıkan faktörleri belirlemeye yönelik olmuştur. Çalışmaların bir kısmında da modeller üretilip, modeller üzerinden çıkarımlar yapılmıştır. Yapılan araştırmaların sonuçlarına göre yapım sektöründe KRY anlayışının yeni yeni yerleştiği, henüz yeterli olgunluğa ulaşmadığı ve bilgi eksikliklerinin mevcut olduğu belirlenmiştir.

\section{Yapım Sektöründe Kurumsal Risk Yönetimi Olgunluğu}

Kurumsal risk yönetimi olgunluğu (Enterprise Risk Management Maturity), kurumsal risk yönetimi uygulamalarının kapsamlılığını yansıtarak, değerlendirme sürecinde uygulamanın güçlü ve zayıf yönlerini meydana çıkararak, ele alınması gereken zayıf noktaların iyileştirilmesi konusunda yönetici ekibe yol gösteren bir yaklaşımdır [24]. Ağırlıklı olarak bankacılık, finans ve sigorta gibi sektörlerde rastladığımı KRY anlayışı yapım sektöründe faaliyet gösteren firmalarda yeni yerleşmeye başlayan bir anlayıştır. Oysaki, birden fazla disiplinle birlikte yürütülen çok paydaşlı bir süreç olarak inşaat projelerinin KRY adaptasyonu konusunda öncül olması beklenmektedir [22]. Yapım sektöründeki karmaşık iş süreçlerinin etkili ve verimli bir şekilde yürütülmesi için olgun ve tam yapılaşmış KRY sistemi önemli bir gereklilik haline gelmiştir. Ancak yapılan çalışmalar incelendiğinde yapım firmalarında KRY olgunluğu ve KRY bilgi düzeylerinin düşük olduğu görülmektedir [23].

\subsection{Kurumsal Risk Yönetimi Olgunluk Modelleri ve KRY Olgunluğu Alanında Yapılan Çalışmalar}

Kurumsal risk yönetimi (KRY) konusunda diğer sektörlerde pek çok çalışma yapılmasına rağmen inşaat sektöründe bu sayı çok azdır. Literatürden farklı sektörlerde kurumsal risk yönetimi konusunda yapılan çalışmalar üzerinden yapım sektörüne yönelik KRY olgunluk modelleri geliştirildiği anlaşılmaktadır. Bu çalışmalar vaka analizleri yapılarak, modeller üzerinde çalışılarak gerçekleştirilmiş ve olgunluk düzeyine etki eden faktörler öne çıkarılmıştır.

Yapım firmalarında yeni tercih edilmeye başlanan kurumsal risk yönetimi yaklaşımının, ana çerçeve olarak henüz tamamlanmamış olduğu yapılan çalışmaların sonuçlarından biridir. Malezya'da yapılan bir vaka çalışmasına göre ele alınan 18 inşaat firmasının henüz 9 tanesinin tam olarak kurumsal risk yönetimi yaklaşımını benimsediği ve uygulamaya koyduğu görülmektedir [2].

Goyannes ve Caiado (2016) çalışmasında yapım firmalarında, KRY olgunluk modellerinin uzmanlarca bilinilirliğini ölçmüş ve KRY olgunluk düzeyini tanımlamada en çok öne çıkan dört unsur belirlenmiştir. Buna göre üst yönetim desteği, risk yönetimi bilgisi, acil eylem planı ve paydaşlarla iletişim üzerinden yapım firmalarında risk yönetim olgunluk düzeyi ölçme olanağı sağlayan yeni bir model geliştirmişlerdir[25].

Bir başka çalışma, kurumsal düzeyde olmasa da inşaat firmalarında var olan risk yönetiminin olgunluğunu ölçmeye yönelik Endonezya'da gerçekleştirilmiştir. Çalışmada öz değerlendirme modeli geliştirilip Caldeon ve Pero (2013), Cienfuegos (2013) ve Ciorciari ile Blattner'in (2015) kullandığı olgunluk seviyesi ölçütlerinden faydalanmıştır. Delphi ve AHP yöntemleriyle yürütülen çalışmada, kamu inşaat projelerinin müşteri kuruluşları için risk yönetim olgunluğunu, organizasyonel kültür, risk yönetimi süreçleri, kaynakları ve uygulamaları olmak üzere dört boyutta ele alınmıştır. Çalışmanın sonucunda insan faktörünün ve organizasyon kültürünün öne çıktığı görülmüştür [26].

Yapım firmalarının kurumsal risk yönetimi olgunluğu konusunda çalışmalarıyla öne çıkan Zhao, literatürden elde ettiği 16 temel kriterle yapım firmalarının olgunluk düzeylerini belirlemiştir. Zhao, KRY olgunluğunun firma büyüklüğüyle pozitif ilişkili olduğu ve de KRY olgunluk düzeylerini artırmaya yönelik hem teknolojik uygulamalara hem de yönetimsel yapilanmalara önem verilmesinin gerekliliği vurgulanmıştır [24].

Zhao (2014) sonraki çalışmasında 16 KRY olgunluk faktörünü etki derecesine göre sıralamış ve etki derecesine göre en yüksek altı faktörü anahtar faktör olarak isimlendirmiştir[24]. Altı anahtar faktör şöyle sıralanabilir;

- F01: Yönetim Kurulu ve üst düzey yönetimin kararlılı̆ 1

○ KRY01 Üst düzey yönetimin KRY uygulamaları konusunda sürekli, kararlı ve teşvik edici olması,

○ KRY02 Üst düzey yönetimin KRY uygulamaları ve yenilikleri çalışanları sürekli olarak bildirmesi 
- F02: Kurumsal risk yönetimine sahip olma

o KRY03 Firmanın KRY uygulamalarını gerçekleştirme sorumluluğunu alarak, müşteri ve yatırımcılarına güven vermesi

○ KRY04 KRY uygulamalarının geliştirilmesi konusunda üst düzey yöneticilerle direkt ve sürekli olarak iletişim içinde bulunulması

- F05Yeterli kaynaklar

○ KRY05 KRY programlarına yeterli bütçe ayrilması

○ KRY06 Uzmanlaşmış KRY grubuyla KRY uygulamalarının ileri seviyede gerçekleştirilmesi

○ KRY07 KRY süreçlerinin yeterli sayıda araç ve çalışan ile yürütülmesi

- F06: Risk tanımlama, analiz ve tepkisi

○ KRY08 Risk kaynakları, riskin sebepleri ve potansiyel etkilerinin kapsamlı olarak tanımlanması

○ KRY09 Nicel risk yönetim araçları ve tekniklerinin kullanılması

○ KRY10 Kurumsal strateji, riskin önemi, risk toleransı ve kaynak mevcudiyeti göz önüne alınarak uygun tepkilerin verilmesi

o KRY11 Tanımlanan riskler arasından anahtar risklerin seçilerek gelecek hedeflerde yol göstermesi açısından KRY uygulamaları tarafindan siklıkla belgelenmesi.

- F14:İş süreçlerine kurumsal risk yönetiminin entegre edilmesi

○ KRY12 Günlük yönetim ve iş süreçlerinin her aşamasına KRY'nin entegre edilmesi

○ KRY13 İş süreçlerinde KRY'nin uygulanma düzeylerinin sürekli olarak kontrol edilip, değerlendirilip, eksik noktaların geliştirilmesi

- F15:Hedeflerin belirlenmesi

○ KRY14 KRY programlarının gidişatına yön veren hedeflerin önceden belirlenmesi

○ KRY15 Olası bir hedef değişikliğinin KRY programina yansitilmasi

○ KRY16 Formüle edilmiş ve yazıya dökülmüş bir demeçle hedeflerin net şekilde anlaşılmasının sağlanması [24].

KRY olgunluğunu etkileyen 6 anahtar faktör, yapım firmalarında KRY olgunluk düzeyini ölçen ve KRY olgunluğunda risk yöneticisinin rolü ile KRY yapılaşması arasındaki ilişkileri inceleyen bu araştırmanın temelini oluşturmuştur.

\section{METODOLOJİ}

\subsection{Araştırmanın Tasarımı ve Kavramsal Altyapısı}

$\mathrm{Bu}$ çalışma, ilişkileri keşfetmeye yönelik nicel bir araştırmayı kapsamaktadır. Temel araştırma hipotezlerinin test edilmesi için gerekli veriler anket alan çalışmasıyla elde edilmiştir. Verilerin analizinde PASW-Statistics programı kullanılmıştır. Veriler, betimsel istatistikler ve ANOVA analiz yöntemleri kullanılarak değerlendirilmiştir. Elde edilen bulgularla bağlantılar ve ilişkiler test edilerek bulguların güvenilirliği ve geçerliliği belirlenmiştir (Şekil 2).

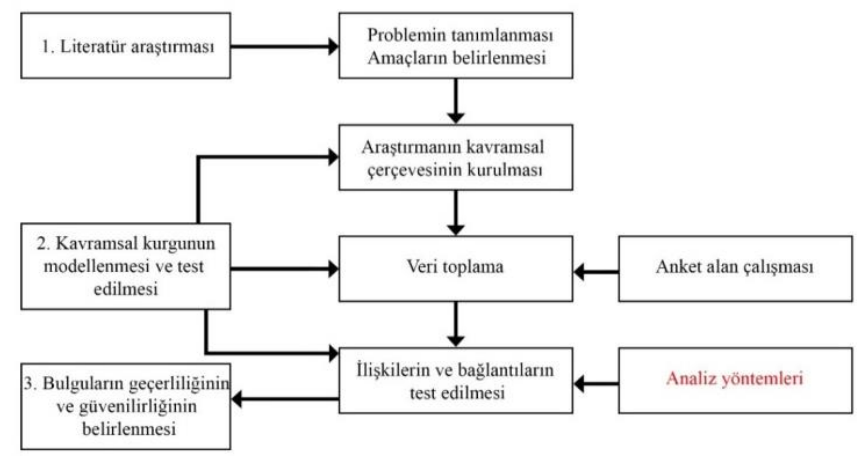

Şekil 2 Araştırmanın Tasarımı ve Uygulaması

\subsection{Araştırmanın Kavramsal Altyapısı}

Kurumsal risk yöneticisi varlığının KRY olgunluğuna etkisini ve bu iki etmenin KRY yapılaşma düzeyiyle ilişkisini incelemek araştırmanın kavramsal altyapısını oluşturmaktadır (Şekil 3). Risk yöneticisinin varlığı, atanmış bir risk yöneticisinin oluşu, olmayışı ve farklı departman altında aynı görevi görüyor oluşu olmak üzere üç temel durum üzerinden değerlendirilmiştir [16]

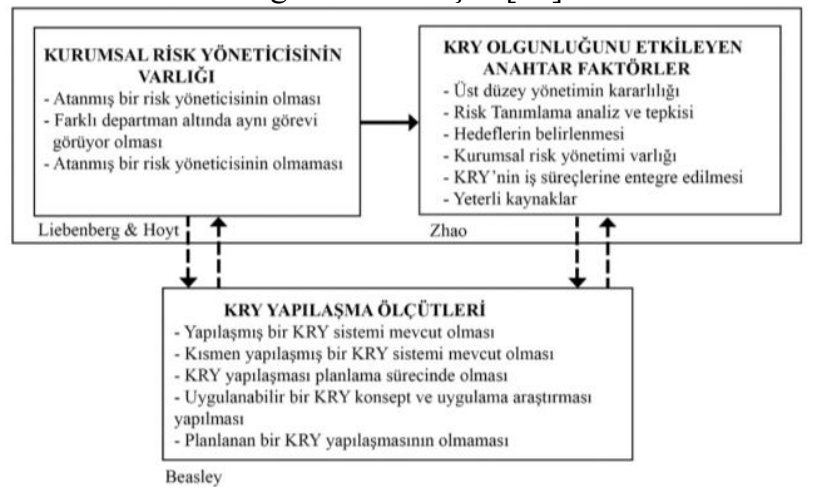

Şekil 3 Araştırmanın Kavramsal Altyapısı

Yapılaşmış bir KRY sisteminin olması, kısmen yapılaşmış bir KRY sisteminin oluşu, KRY'nin planlanma sürecinde oluşu, uygulanabilir bir KRY konseptinin araştırılıyor oluşu ve planlanan bir KRY yapılaşmasının olmayışı KRY yapılaşma ölçütlerini oluşturmaktadır [27]. KRY olgunluğunu ölçümü ise Zhao (2013)'nun 6 anahtar faktörü üzerinden gerçekleştirilmiştir [28].

\subsection{Anket Alan Çalışması}

Risk yöneticisinin varlığının kurumsal risk yönetimine etkisini ve KRY yapılaşmasıyla ilişkisini inceleyen araştırma için anket alan çalışması gerçekleştirilmiştir. Anket, dört bölümden oluşmaktadır. Birinci bölüm, katılımcıyla ilgili bilgi edinme amaçlı soruları içermektedir. İkinci bölüm, firmayla ilgili bilgilerin edinildiği bölümdür. Üçüncü bölüm, firmanın KRY varlığ 1 , risk yönetim süreci, risk yöneticisinin varlığı ve KRY yapılaşma düzeyi ile ilgili soruları içeren 
bölümdür. Dördüncü bölüm KRY olgunluk düzeyini etkileyen 6 anahtar faktörün 16 parametresinin KRY olgunluğuna olan etkisi inceleyen bölümdür.

\section{4. Örneklem}

Türk Müteahhitler Birliği’ne üye olan yapım firmalarının çalışanlarına LinkedIn üzerinden ulaştırılan anket aracılığıyla yapılan çalışma, 24.12.2018 - 06.02.2019 tarihleri arasında gerçekleştirilmiştir. 670 kişiye ulaştırılan anket alan çalışması, 95 kişinin yanıtıyla sonuçlanmış, geri dönüş oranı \%14 olarak belirlenmiştir.

\subsection{Araştırma Verilerinin Analizi ve Yorumu 5.5.1 Betimsel İstatistikler}

\section{Anket Katılımcılarının Demografik Özellikleri}

Yapım firmalarında görev alan 95 kişinin katılımıyla gerçekleştirilen anket sonuçlarına göre, katılımcıların \%4,2'sinin yaşı 25 'ten küçük, \%58,9'u'sının yaşı 26-39 yaş aralığında, \%35,8'inin yaşı 40-59 yaş aralığında iken, \% 1,1 'i 60 yaş ve üzerinde olduğu tespit edilmiştir. Katılımcı grubun genç ve orta yaş grubunda olduğu görülmüştür (Tablo 3).

Tablo 3 Anket Katılımcılarının Demografik Özellikleri

\begin{tabular}{|l|c|c|}
\hline & SIKLIK & $\%$ \\
\hline Yaş & & \\
\hline 25 'ten küçük & 4 & 4,2 \\
$26-39$ & 56 & 58,9 \\
$40-59$ & 34 & 35,8 \\
60 ve üstü & 1 & 1,1 \\
\hline Ĕgitim durumu & & \\
\hline Lise & 1 & 1,1 \\
\hline Üniversite & 58 & 61,1 \\
\hline Yüksek lisans ve üstü & 36 & 37,9 \\
\hline
\end{tabular}

Katılımcıların firmalardaki pozisyonları inşaat mühendisi, proje müdürü, kurumsal risk koordinatörü, planlama mühendisi, risk yönetimi mühendisi, proje kontrol mühendisi, teknik ofis yöneticisi, yapım yöneticisi, genel müdür, üst düzey yönetici finansal kontrol ve raporlama mühendisi, proje koordinatörü, sözleşme yöneticisi ve yönetim kurulu üyesidir.

Firmalardaki kurumsal risk yönetimi (KRY) varlığl Firmaların KRY varlığını öğrenmek üzere yöneltilen soruya katılımcıların \%57,9'u evet olarak, \%42,1 i hayır olarak yanıtlamıştır (Tablo 4).

Tablo 4 Firmalardaki KRY Varlı̆̆

\begin{tabular}{|c|c|c|c|c|}
\hline & SIKLIK & YÜZDE & GEÇERLI YÜZDE & $\begin{array}{c}\text { KÜMÜLATIF } \\
\text { YÜZDE }\end{array}$ \\
\hline Hayır & 40 & 42,1 & 42,1 & 42,1 \\
\hline Evet & 55 & 57,9 & 57,9 & 100,0 \\
\hline
\end{tabular}

\section{Firmaların KRY yapılaşma düzeyleri}

Anket verilerine göre firmaların \%24,2'si yapılaşmış bir KRY sistemine sahiptir. Kısmen yapılaşmış KRY sistemine sahip firmaların oranı ise $\% 8,4$ olarak ölçülmüştür. KRY yapılaşması planlama sürecinde olan firmaların oranı $\% 14,7$ iken uygulanabilir bir KRY konsept ve uygulama araştırması yapan firmaların oranı $\% 29,5$ 'tir. Katılım gösteren firmaların \%23,2'sinde ise planlanan bir KRY yapılaşması yoktur (Tablo 5).

Tablo 5 Firmaların KRY Yapılaşma Düzeyleri

\begin{tabular}{|l|c|c|c|c|}
\hline & SIKLIK & YÜZDE & $\begin{array}{c}\text { GEÇERLI } \\
\text { YÜZDE }\end{array}$ & $\begin{array}{c}\text { KÜMÜLATIF } \\
\text { YÜZDE }\end{array}$ \\
\hline $\begin{array}{l}\text { Yapılaşmış bir KRY sistemi } \\
\text { mevcut. }\end{array}$ & 23 & 24,2 & 24,2 & 24,2 \\
\hline $\begin{array}{l}\text { Kısmen yapılaşmış bir KRY } \\
\text { sistemi mevcut. }\end{array}$ & 8 & 8,4 & 8,4 & 32,6 \\
\hline $\begin{array}{l}\text { KRY yapılaşması planlama } \\
\text { sürecinde. }\end{array}$ & 14 & 14,7 & 14,7 & 47,4 \\
\hline $\begin{array}{l}\text { Uygulanabilir bir KRY konsept } \\
\text { ve uygulama araştırması } \\
\text { yapılliyor }\end{array}$ & 28 & 29,5 & 29,5 & 76,8 \\
\hline $\begin{array}{l}\text { Planlanan bir KRY yapılaşması } \\
\text { yok. }\end{array}$ & 22 & 23,2 & 23,2 & 100,0 \\
\hline
\end{tabular}

Firmalardaki risk yöneticisi varlı̆̆

Firmaların \%38,9'unda atanmış bir risk yöneticisi mevcutken, \%24,2'sinde aynı görevi yapan farklı bir departman bulunmaktadır. \%36,8'inde ise atanmış bir risk yöneticisi bulunmamaktadır (Tablo 6).

Tablo 6 Risk Yöneticisi Varlığ

\begin{tabular}{|l|c|c|c|c|}
\hline & SIKLIK YÜZDE & $\begin{array}{c}\text { GEÇERLİ } \\
\text { YÜZDE }\end{array}$ & $\begin{array}{c}\text { KÜMÜLATIF } \\
\text { YÜZDE }\end{array}$ \\
\hline $\begin{array}{l}\text { Atanmış bir risk yöneticisi } \\
\text { mevcut. }\end{array}$ & 37 & 38,9 & 38,9 & 38,9 \\
\hline $\begin{array}{l}\text { Farklı bir departman altında } \\
\text { ancak aynı görevi yapıyor. }\end{array}$ & 23 & 24,2 & 24,2 & 63,2 \\
\hline $\begin{array}{l}\text { Atanmış bir risk yöneticisi } \\
\text { yok. }\end{array}$ & 35 & 36,8 & 36,8 & 100,0 \\
\hline
\end{tabular}

\section{Firmalarca göz önünde bulundurulan risk grupları}

Farklı risk gruplarına maruz kalındığı bir sektör olan yapım sektöründe finansal, operasyonel, stratejik ve çevresel risklerden en çok göz önünde bulundurulan risk grubu finansal risk grubu olmuştur. Belirli bir maliyet planlaması kapsamında yürütülen ve piyasa koşullarından etkilenen iş ağına sahip olan yapım sektöründe faaliyet gösteren firmaların en çok finansal riskleri göz önünde bulundurması kaçınılmazdır. Finansal risklerden sonra daha fazla göz önünde bulundurulan risk grupları operasyonel ve stratejik riskler olmuştur (Şekil 4). Disiplinler arası çalışmaların sergilendiği bir sektör olan yapım sektöründe operasyonel risklerin önemi büyüktür. Kurumsal risk yönetimin temel unsurlarından biri olan hedeflerin belirlenmesi, firma stratejisine yön vererek bu alandaki risklerin tanımlanması, analizi ve tepkisinin önemini ortaya koyar. $\mathrm{Bu}$ sebeple 
stratejik risklerin göz önünde bulundurulma firma amaç ve hedefleri açısından anlamlıdır.

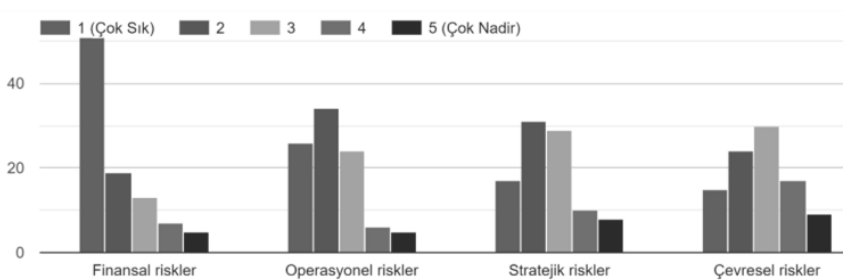

Şekil 4 Firmalarca Göz Önünde Bulundurulan Risk Gruplar1

KRY uygulamalarının firmalara sağladı ̆̆ı getiriler

Anket katılımcılarının cevaplarına göre KRY uygulamalarının firmalara sağladığı getirilere ilişkin öne çıkan üç temel getiri; proje kontrolünde gelişmişlik, kaynakların verimli kullanımı ve gelişmiş finansal stabilite olmuştur (Şekil 5).

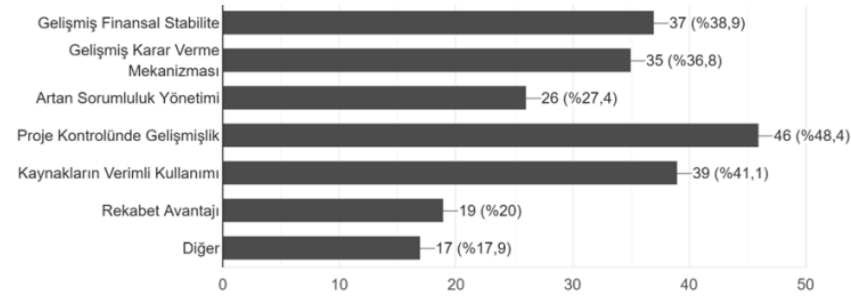

Şekil 5 KRY uygulamalarının firmalara sağladığı getiriler

\subsubsection{ANOVA Analizi}

Faktör veya faktörlerin istatistiksel olarak anlamlı olup olmadığını belirlemek için deney birimlerinden elde edilen gözlem değerlerine uygulanan tekniğe Varyans Analizi (ANalysis Of VAriance - ANOVA) denir. İkiden fazla grup durumunda parametrelerin gruplar arası karşılaştırmalarında Tek yönlü (One way) Anova testi kullanılır.

KRY olgunluk düzeyine etki eden parametrelerin KRY yapılaşması varlığı ile ilişkisinin ANOVA analiz sonuçları Tablo 7 'de verilmiştir, gruplar arasındaki farkı belirleyebilmek için Tukey testi kullanılarak anlamlılık düzeyi $\mathrm{p}<0,01$ alınmıştır.

Tablo 7 KRY olgunluk düzeyine etki eden parametreler ve KRY yapılaşması varlı̆̆ı: ANOVA Analizi

\begin{tabular}{|c|c|c|c|c|c|c|}
\hline KRY Y & $\begin{array}{l}\text { ŞMASI } \\
\text { SI }\end{array}$ & $\mathbf{N}$ & ODTI & STD. & F & SİG. \\
\hline KRY-01 & HAYIR & 40 & 2,32 & 1,24 & 29,5 &, $00^{*}$ \\
\hline & EVET & 55 & 3,63 & 1,09 & & \\
\hline KRY-02 & HAYIR & 40 & 2,25 & 1,40 & 16,6 &, $00^{*}$ \\
\hline & EVET & 55 & 3,36 & 1,23 & & \\
\hline KRY-03 & HAYIR & 40 & 2,32 & 1,24 & 22,4 &, $00^{*}$ \\
\hline & EVET & 55 & 3,50 & 1,16 & & \\
\hline KRY-04 & HAYIR & 40 & 2,52 & 1,32 & 17,9 &, $00^{*}$ \\
\hline & EVET & 55 & 3,56 & 1,06 & & \\
\hline KRY-05 & HAYIR & 40 & 2,02 & 1,22 & 19,9 &, $00^{*}$ \\
\hline & EVET & 55 & 3,14 & 1,19 & & \\
\hline KRY-06 & HAYIR & 40 & 2,05 & 1,17 & 22,2 &, $00^{*}$ \\
\hline & EVET & 55 & 3,27 & 1,29 & & \\
\hline KRY-07 & HAYIR & 40 & 2,02 & 1,16 & 23,7 &, $00^{*}$ \\
\hline & EVET & 55 & 3,23 & 1,21 & & \\
\hline KRY-08 & HAYIR & 40 & 2,42 & 1,12 & 27,2 &, $00^{*}$ \\
\hline & EVET & 55 & 3,60 & 1,04 & & \\
\hline KRY-09 & HAYIR & 40 & 2,27 & 1,15 & 34,8 &, $00 *$ \\
\hline & EVET & 55 & 3,54 & ,93 & & \\
\hline KRY-10 & HAYIR & 40 & 2,27 & 1,08 & 34,2 &, $00^{*}$ \\
\hline & EVET & 55 & $\underline{3,58}$ & 1,06 & & \\
\hline KRY- & HAYIR & 40 & 2,22 & 1,12 & 34,9 &, $00 *$ \\
\hline & EVET & 55 & 3,56 & 1,06 & & \\
\hline KRY-12 & HAYIR & 40 & 2,15 & 1,14 & 21,2 &, $00 *$ \\
\hline & EVET & 55 & 3,20 & 1,06 & & \\
\hline KRY-13 & HAYIR & 40 & 2,22 & 1,16 & 24,3 &, $00 *$ \\
\hline & EVET & 55 & 3,40 & 1,13 & & \\
\hline KRY-14 & HAYIR & 40 & 2,35 & 1,12 & 22,5 &, $00^{*}$ \\
\hline & EVET & 55 & 3,45 & 1,11 & & \\
\hline KRY-15 & HAYIR & 40 & 2,27 & 1,21 & 25,2 &, $00^{*}$ \\
\hline & EVET & 55 & 3,50 & 1,15 & & \\
\hline KRY-16 & HAYIR & 40 & 2,30 & 1,20 & 22,7 &, $00^{*}$ \\
\hline & EVET & 55 & 3,50 & 1,23 & & \\
\hline$*(\mathrm{p}<0,05$ & & & & & & \\
\hline
\end{tabular}

Yapılan ANOVA analizi sonuçları tüm parametreler için KRY yapılaşması varlığı durumları arasında anlamlı bir farkl1lık bulunduğunu göstermektedir $(\mathrm{p}<0,01)$. 
Tablo 8 KRY olgunluk parametreleri ve risk yöneticisinin varlı̆̆ı: ANOVA Analizi

\begin{tabular}{|c|c|c|c|c|c|c|}
\hline \multicolumn{2}{|c|}{$\begin{array}{c}\text { RISK YÖNETİCISINININ } \\
\text { VARLIĞI }\end{array}$} & \multirow{2}{*}{$\frac{\mathbf{N}}{37}$} & \multirow{2}{*}{\begin{tabular}{|c|} 
ORTL. \\
2,37 \\
\end{tabular}} & \multirow{2}{*}{\begin{tabular}{|c|c|}
$\begin{array}{c}\text { STD. } \\
\text { SAPMA }\end{array}$ \\
1,27 \\
\end{tabular}} & \multirow{2}{*}{$\begin{array}{c}\mathbf{F} \\
12,9\end{array}$} & \multirow{2}{*}{\begin{tabular}{|l} 
SİG. \\
, $00^{*}$
\end{tabular}} \\
\hline \multirow[t]{3}{*}{ KRY-01 } & VAR. & & & & & \\
\hline & KISMİ & 23 & 3,13 & 1,09 & & \\
\hline & YOK & 35 & 3,80 & 1,13 & & \\
\hline \multirow[t]{3}{*}{ KRY-02 } & VAR & 37 & 2,13 & 1,29 & 13,0 & $00 *$ \\
\hline & KISMİ & 23 & 2,95 & 1,22 & & \\
\hline & YOK & 35 & 3,65 & 1,25 & & \\
\hline \multirow{3}{*}{ KRY-03 } & VAR & \begin{tabular}{|l|}
37 \\
\end{tabular} & 2,37 & 1,34 & 9,8 &, $00 *$ \\
\hline & KISMİ & 23 & \begin{tabular}{|l|}
3,04 \\
\end{tabular} & 1,14 & & \\
\hline & YOK & 35 & 3,65 & 1,13 & & \\
\hline \multirow[t]{3}{*}{ KRY-04 } & VAR. & 37 & 2,35 & 1,27 & 17,5 &, $00 *$ \\
\hline & KISMİ & 23 & 3,21 & ,90 & & \\
\hline & YOK & 35 & 3,88 & 1,02 & & \\
\hline \multirow[t]{3}{*}{ KRY-05 } & VAR & 37 & 1,97 & 1,30 & 11,5 &, $00 *$ \\
\hline & KISMİ & 23 & 2,82 & 1,02 & & \\
\hline & YOK & 35 & 3,31 & 1,18 & & \\
\hline \multirow[t]{3}{*}{ KRY-06 } & VAR & 37 & \begin{tabular}{|l|}
1,97 \\
\end{tabular} & 1,23 & 19,5 &, $00^{*}$ \\
\hline & KISMİ & 23 & 2,60 & ,98 & & \\
\hline & YOK & 35 & 3,68 & 1,20 & & \\
\hline \multirow[t]{3}{*}{ KRY-07 } & VAR. & & & & 14,3 &, $00 *$ \\
\hline & KISMI & \begin{tabular}{|l|}
23 \\
\end{tabular} & 2,73 & 1,13 & & \\
\hline & YOK & 35 & 3,48 & 1,19 & & \\
\hline \multirow[t]{3}{*}{ KRY-08 } & VAR & \begin{tabular}{|l|}
37 \\
\end{tabular} & \begin{tabular}{|l|}
2,40 \\
\end{tabular} & 1,16 & 19,0 &, $00 *$ \\
\hline & KISMİ & 23 & 3,00 &, 85 & & \\
\hline & YOK & 35 & 3,91 & 1,01 & & \\
\hline \multirow[t]{3}{*}{ KRY-09 } & VAR & 37 & 2,29 & 1,19 & 15,8 &, $00 *$ \\
\hline & KISMI & 23 & 3,13 & ,96 & & \\
\hline & YOK & 35 & 3,68 & ,93 & & \\
\hline \multirow[t]{3}{*}{ KRY-10 } & VAR. & 37 & 2,37 & 1,18 & 13,5 & ,00* \\
\hline & KISMİ & 23 & 3,00 & 1,12 & & \\
\hline & YOK & 35 & \begin{tabular}{|l|}
3,74 \\
\end{tabular} & 1,01 & & \\
\hline \multirow[t]{3}{*}{ KRY-11 } & VAR & 37 & 2,27 & 1,17 & 15,1 &, $00 *$ \\
\hline & KISMİ & 23 & 3,08 & 1,12 & & \\
\hline & YOK & 35 & 3,71 & 1,04 & & \\
\hline \multirow[t]{3}{*}{ KRY-12 } & VAR & 37 & 2,13 & 1,13 & 13,7 &, $00 *$ \\
\hline & KISMİ & 23 & 2,69 & 1,06 & & \\
\hline & YOK & 35 & 3,45 & 1,01 & & \\
\hline \multirow[t]{3}{*}{ KRY-13 } & VAR. & 37 & 2,18 & 1,12 & 17,2 &, $00 *$ \\
\hline & KISMI & 23 & 2,82 & 1,26 & & \\
\hline & YOK & 35 & 3,71 &, 95 & & \\
\hline \multirow[t]{3}{*}{ KRY-14 } & VAR & \begin{tabular}{|l|}
37 \\
\end{tabular} & 2,24 & 1,16 & 17,8 &, $00 *$ \\
\hline & KISMİ & 23 & \begin{tabular}{|l|}
3,04 \\
\end{tabular} & ,92 & & \\
\hline & YOK & 35 & 3,74 & 1,03 & & \\
\hline \multirow[t]{3}{*}{ KRY-15 } & VAR & \begin{tabular}{|l|}
37 \\
\end{tabular} & 2,18 & 1,19 & 16,7 &, $00 *$ \\
\hline & KISMİ & 23 & 3,13 & 1,05 & & \\
\hline & YOK & 35 & 3,74 & 1,14 & & \\
\hline KRY-16 & VAR & 37 & 2,21 & 1,20 & 18,0 &, $00 *$ \\
\hline & KISMI & 23 & 2,95 & 1,18 & & \\
\hline & YOK & 35 & 3,85 & 1,08 & & \\
\hline & $*(\mathrm{p}<0,05)$ & & & & & \\
\hline
\end{tabular}

Tablo 7'de KRY yapılaşmasının olmadı ̆̆ı durumlarda KRY olgunluğuna etki eden parametrelerin değerleri ortalamanın altında ölçülmüşken; KRY yapılaşmasının varlığı durumunda KRY olgunluğuna etki eden parametrelerin ortalama değerlerinin ortalamanın üzerinde ve daha yüksek olduğu görülmüştür. KRY yapılaşmasına sahip firmalar için 16 parametre arasından etki düzeyi en yüksek olan üç parametre ise şu şekilde sıralanabilir:
- $\quad$ Üst düzey yönetimin KRY uygulamaları konusunda sürekli, kararlı ve teşvik edici olması

- Risk kaynakları, riskin sebepleri ve potansiyel etkilerinin kapsamlı olarak tanımlanması

- $\quad$ Kurumsal strateji, riskin önemi, risk toleransı ve kaynak mevcudiyeti göz önüne alınarak uygun tepkilerin verilmesi.

KRY olgunluk parametrelerinin farklılaşmasını, risk yöneticisinin varlığına göre karşılaştıran ANOVA analizine göre ise risk yöneticisinin varlığı ve KRY olgunluğunu etkileyen parametreler arasında anlamlı bir farklılık vardır ( $\mathrm{p}$ $<$ 0,05). Tablo 8'ya göre, atanmış bir risk yöneticisi varlığında KRY olgunluk parametreleri ortalamanın altında değerlere sahipken, atanmış bir risk yöneticisi olmaması durumunda KRY olgunluğuna etki eden parametrelerin ortalama değerleri daha yüksek ve ortalama değerin üzerinde ölçülmüştür.

$\mathrm{Bu}$ ilişkiler arasında etki değeri en yüksek olarak ölçülen parametreler;

- $\quad$ Üst düzey yönetimin KRY uygulamaları konusunda sürekli, kararlı ve teşvik edici olması

- $\quad$ KRY uygulamalarının geliştirilmesi konusunda üst düzey yöneticilerle direkt ve sürekli olarak iletişim içinde bulunulması

- $\quad$ Formüle edilmiş ve yazıya dökülmüş bir demeçle hedeflerin net şekilde anlaşılmasının sağlanması olmuştur.

\section{SONUÇ}

Risklerle karşılaşmanın kaçınılmaz olduğu yapım sektöründe faaliyet gösteren firmalar için KRY uygulamalarını geliştirmek firmaların sürdürülebilir başarısı için önem kazanmaktadır. KRY olgunluk düzeylerini yükseltici ve KRY ile ilgili eksik bilgilerin giderilebileceği çalışmalar yapılarak farkındalık sağlanmalıdır. $\mathrm{Bu}$ çalışmalardan elde edilecek bilgiler teknolojik kaynaklarla da desteklenerek iş süreçlerinde en yüksek seviyede fayda sağlanmalıdır.

Literatürde, iş süreçlerinin çok paydaşlı yapısına ve kapsamı ve niteliği sebebiyle risklere maruz kalma olasılığının bir hayli fazla olduğu yapım sektörünün KRY'yi benimsemede öncül bir sektör olması gerekliliğine vurgu yapılmıştır. KRY, firma ve paydaş değerlerine katkıda bulunan, firma strateji ve hedeflerine bütüncül bir yaklaşımla yön vererek etkili risk analiz ve yönetim süreçlerine olanak sağlayan yeni bir yaklaşımdır.

Bu çalışma kapsamında, yapım firmalarında KRY olgunluk düzeyi değerlendirilmiş, risk yöneticisinin ve KRY yapılaşması varlığının KRY olgunluk düzeylerine etkileri araştırılmıştır. Çalışmanın temel sonuçları şu şekilde özetlenebilir: 
- $\quad$ KRY olgunluğuna etkisinde ortalamanın üzerinde değerler alarak en çok öne çıkan iki faktör "KRY'ye sahip olma (F-02)" ile "Risk tanımı, analiz ve tepkisi (F-06)" olmuştur. "KRY'ye sahip olma (F-02)" faktörü, KRY uygulamalarının üst düzey yönetim ile sürekli iletişim halinde olarak geliştirilmesini beraberinde getirmektedir. Ayrıca, üst düzey yönetimin KRY uygulamaları konusunda aktif ve istekli olması organizasyon içerisinde sürekli iletişimle KRY uygulamalarının geliştirilerek devam etmesi KRY olgunluğu için kritik önem taşımaktadır. Kurumsal risk yönetiminin temel unsurlarından biri olarak nitelendirilen "risk tanımı, analizi ve tepkisi", firmanın hedeflerine göre şekil alan bir süreçtir. Elde edilen sonuçlara göre, yapım firmalarında hedefler doğrultusunda ve stratejilere uygun olarak gerçekleştirilen risk tanımı, analiz ve tepkisi süreci firmaların KRY işlevinin en önemli bileşenidir. Araştırmada temel alınan anahtar faktörlerin altyapısını oluşturan Zhao'nun (2013) çalışmasında da risk tanımı, analiz ve tepkisi en yüksek etki seviyesine sahip ikinci faktör olarak belirlenmiştir [28]. Kuruluşların, kurumsal risk yönetimini hedef ve amaçlarına uyarlayarak riskleri tanımlaması, değerlendirmesi, tepki vermesi ve gözlemleyerek ilgili bölümlere rapor etmesi KRY'nin temel unsurlarını oluşturmaktadır (GAO) ve kurumsal firmalarda başarıyı yakalamada kritik bir faktördür [29]. Arena vd. [29] ile GAO tarafından da önemi vurgulanan "risk analiz, tanımı ve tepkisi faktörü" bu çalışma sonuçlarına göre de KRY olgunluğunda anlamlı bir etkiye sahiptir.

- $\quad$ ANOVA analiziyle, hem risk yöneticisinin varlığının hem de KRY yapılaşmasının varlığının KRY olgunluğunda yarattığ1 fark ölçülmüşsür. Elde edilen sonuçlara göre, araştırmanın çıkış noktası olan risk yöneticisinin varlığının KRY olgunluğuna olumlu olarak etki edeceği hipotezi beklenen sonucu vermemiştir. Başka bir deyişle, tek başına risk yöneticisinin varlığı KRY olgunluğunda etkili değildir. Diğer yandan, ANOVA analiziyle KRY yapılaşmasının varlığının KRY olgunluğuna etkisi araştırılmıştır ve olumlu etkilediği görülmüştür. $\mathrm{Bu}$ sonuca göre risk yöneticisinin varlığından çok organizasyon içerisinde yerleşmiş bir KRY yapılaşmasının varlığının KRY olgunluğunda etkili olduğu sonucuna ulaşılmıştır. Beasley vd. çalışmalarının sonucunda atanmış bir risk yöneticisinin varlığının KRY adaptasyonunda ve benimsenmesinde önemli bir faktör olduğunu belirtmişlerdir. Tüm bu bilgiler 1şığında risk yöneticisinin varlığının KRY olgunluğuna olumlu etki etmesi beklenirken, tek başına yeterli olmadığı sonucuna varılmıştır [30]. Bir diğer yandan, risk yöneticisinin varlığı da KRY yapılaşmasını olumlu etkileyecek bir faktördür.

Çalışmanın sonucuna göre, KRY yapılaşmasının varlığının KRY olgunluğuna etkisi anlamlıdır, bu sonucu COSO'nun KRY tanımı da destekler niteliktedir. COSO'nun KRY tanımında, kurumsal risk yönetimi, organizasyon içerisinde çeşitli düzeydeki risk yöneticilerinin ve çalışanlarının dâhil olduğu, aktif bir süreç olarak değerlendirilmiştir. Özetle, risk yöneticisi düzeyinde kalan bir KRY süreci değil, organizasyon düzeyinde ve organizasyon genelinde yürütülen KRY süreçlerinin KRY olgunluğuna olumlu etkisi bu çalışmanın en temel bulgusudur[1].

- KRY yapılaşması olan firmalarda yeterli kaynakların önemi ve verimli kullanımına ilişkin firma düzeyinde eğitimler ve uygulamalar yapılarak farkındalık pekiştirilmelidir. KRY'nin iş süreçlerine entegre edilme düzeyi KRY sisteminin yapılaşma düzeyiyle doğru orantılıdır. Yeterli kaynakların kullanılarak iş süreçlerine KRY'yi entegre etmek, yapım firmalarının KRY yapılaşma düzeyini geliştirerek etkili ve verimli KRY süreçlerine olanak sağlayacaktır. Ayrıca risk yöneticisinin verilen tepkileri gözlemlenmesi, KRY süreci içerisinde üst düzey yönetim ve çalışanlar arasında bilgi akışını sağlayan bağlayıcı aktör rolünü oynaması önemlidir.

$\mathrm{Bu}$ çalışma, yapım firmaları bağlamında KRY olgunluk düzeyini, risk yöneticisi varlığı ve KRY yapılaşması varlığ1 ile ilişkilendirerek araştırmıştır. Düşük olarak ölçülen KRY olgunluk ve yapılaşma düzeylerini iyileştirmeye, risk yöneticisinin varlığının önemine ilişkin farkındalığı sağlamaya yönelik yapılacak çalışmalar yapım sektöründeki KRY süreçlerinin geliştirilmesine olanak sağlayacaktır.

\section{KAYNAKÇA}

[1] COSO - Committee of Sponsoring Organizations of the Treadway Commission, "Enterprise risk managementintegrated framework: executive summary," Committee of Sponsoring Organizations of the Treadway Commission, New York, 2004.

[2] S. Soltanizadeha, S. Z. A. Rasida, N. Golshanb, F. Quoquaba ve R. Basiruddina, "Enterprise risk management practices among Malaysian firms," International Conference on Accounting Studies ( ICAS), Kuala Lumpur, Malaysia, 2014.

[3] X. Zhao, B. Hwang, ve S. Pheng Low, "Enterprise risk management implementation in construction firms: An organizational change perspective,"Management Decision, vol. 52 no. 5, pp. 814-833, 2014.

[4] J. Y. Liu, P.X.W. Zou ve W. Gong, "Managing project risk at enterprise level: exploratory case studies in China," Journal of Construction Engineering and Management, vol. 139, no. 9, pp. 1268-1274, 2013.

[5] S. Adibi, "Industry should embrace risk management tools," New York Construction News, February, 2011.

[6] G.A. Holton, "Closed Form Value at Risk," Working Paper, Contingency Analysis, Boston, July 25, 2002.

[7] J. Deragon, "Old knowledge with a new name. Online publishing," Erisk.com, November, 2000. [Online]. Available: http://www.Erisk.com. [Access Sept. 27, 2015].

[8] R. Banham, "Kit and Caboodle: Understanding the Skepticism about Enterprise Risk Management," CFO Magazine, April, p. 63, 1999.

[9] J. Miccolis, ve S. Shah, "Enterprise Risk Management: An Analytic Approach," Tillinghast-Towers Perrin Monograph, New York, 2000.

[10] Institute of Internal Auditors (IIA), "Risk or Opportunity - the Choice Is Yours," Tone at the top, vol. 11, para. 20, September, 2001. 
[11] T. T. Perrin, “Creating Value through Enterprise Risk Management - a Practical Approach for the Insurance Industry," A Tillinghast-Towers Perrin Monograph Risk Value Insights, 2001. [Online]. Avaiable: http://ermworkingparty.pbworks.com/f/Value+through+ER M+TP+2002051306.pdf. [Accessed Dec. 10, 2018].

[12] S.P. D'Arcy ve J.C. Brogan, "Enterprise risk management," Journal of Risk Management of Korea, vol. 12, no. 1, pp. 207-228, 2001.

[13] G. Dickinson, "Enterprise risk management: its origins and conceptual foundations," The Geneva Papers on Risk and Insurance-Issues and Practice, vol. 26, no. 3, pp. 360366, 2001.

[14] S.E. Harrington, G. Niehaus ve K.J. Risko, "Enterprise risk management: the case of united grain growers," Journal of Applied Corporate Finance, vol. 14, no. 4, pp. 71-81, 2002.

[15] T. Barton, W. Shenkir ve P. Walker, Making Enterprise Risk Management Pay off. Upper Saddle River, NJ: Prentice PTR Hall, 2002.

[16] A.P. Liebenberg ve R.E. Hoyt, "The determinants of enterprise risk management: evidence from the appointment of chief risk officers," Risk Management and Insurance Review, vol. 6, no. 1, pp. 37-52, 2003.

[17] D. Sprčić, A. Kožul ve E. Pecina, "Managers' Support - A Key Driver behind Enterprise Risk Management Maturity," Zagreb International Review of Economics and Business, vol. 20, no. 1, pp. 25-39, 2017.

[18] N.A. Manab, I. Kassim ve M.R. Hussin, "Enterprisewide risk management (EWRM) practices: between corporate governance compliance and value creation," International Review of Business Research Papers, vol. 6 no. 2, pp. 239-252, 2010.

[19] D. Wu ve D.L. Olson, "Enterprise risk management: small business scorecard analysis," Journal of Production Planning \& Control, vol. 20, no. 4, pp. 362-369, 2009.

[20] P. Bromiley, M.K. McShane, A. Nair ve E. Rustambekov, "Enterprise Risk Management: Review, Critique, and Research Directions," Long Range Planning, vol. 48, no. 4, pp. 265-276, 2015.

[21] B. Weinstein, K. Blacker ve R. Mills, "Risk management for nonexecutive directors: creating a culture of cautious innovation," Henley Discussion Paper no. 2, Henley
Management College, 2003.

[22] X. Zhao,B. G. Hwang, B G ve S. P. Low, "Implementing enterprise risk management in a Chinese construction firm based in Singapore," Proceedings of World Construction Conference 2012 (CIB W107), 28-30 June, 2012, pp. 434444.

[23] A. Serpell, X. Ferrada, L. Rubio ve S. Arauzo, "Evaluating Risk Management Practices in Construction Organizations," Procedia - Social and Behavioral Sciences, pp. 201-210, 2015.

[24] X. Zhao, B. Hwang, M. ASCE ve S. P. Low, "Investigating Enterprise Risk Management Maturity in Construction Firms," Journal of Construction Engineering and Management, vol. 140, no. 8, pp. 05014006/1-10, 2014. [25] R. Caiado, G. Lima, D. Nascimento, J. Vieira Neto ve R. de Oliveira, "Guidelines to Risk Management Maturity in Construction Projects," Brazilian Journal of Operations \& Production Management, vol. 13, no. 3, pp. 372-385, 2016. [26] A. Wibowo ve J. Taufik, "Developing a Self-assessment Model of Risk Management Maturity for Client Organizations of Public Construction Projects: Indonesian Context," Procedia Engineering, vol. 171, pp. 274-281, 2017.

[27] M. Beasley, B. Branson ve B. Hancock, "The state of risk oversight - An overview of enterprise risk management practices," AICPA Poole College of Management Enterprise Risk Management Iniative, pp. 1-17,2017.

[28] X. Zhao, B. Hwang ve S. Low, "Critical success factors for enterprise risk management in Chinese construction companies, "Construction Management and Economics, pp. 1199-1214, 2013.

[29] M. Arena, M. Arnaboldi ve G. Azzone,(2011). 'Is enterprise risk management real," Journal of Risk Research, vol. 14, no. 7, 2011.

[30] M. S. Beasley, R. Clune ve D. R. Hermanson, "Enterprise Risk Management: An Empirical Analysis of Factors Associated with the Extent of Implementation," The Journal of Accounting and Public Policy, vol. 24, no. 1, pp. 521-531, 2005.

[31] K. Ar1, "Yapım Firmalarının Kurumsal Risk Yönetimi Olgunluğunda Risk Yöneticisinin Rolü," Yüksek Lisans Tezi, Yıldız Teknik Üniversitesi Fen Bilimleri Enstitüsü, Mimarlık Anabilim Dalı, İstanbul, 2019. 